\title{
Anthropometric cutoff values for detecting metabolic abnormalities in Jordanian adults
}

This article was published in the following Dove Press journal:

Diabetes, Metabolic Syndrome and Obesity:Targets and Therapy

17 November 2010

Number of times this article has been viewed

\author{
Yousef S Khader' \\ Anwar Batieha' \\ Hashim Jaddou' \\ Zahi Batieha ${ }^{2}$ \\ Mohammed El-Khateeb ${ }^{3}$ \\ Kamel Ajlouni ${ }^{3}$ \\ 'Department of Community Medicine. \\ Public Health and Family Medicine, \\ Faculty of Medicine, Jordan University \\ of Science and Technology, Irbid, \\ Jordan; ${ }^{2}$ King Abdullah University \\ Hospital, Irbid, Jordan; ${ }^{3}$ National \\ Center for Diabetes, Endocrinology \\ and Genetics, Amman, Jordan
}

Correspondence: Yousef S Khader Department of Community Medicine, Public Health and Family Medicine, Faculty of Medicine, Jordan University of Science and Technology, PO Box 3030 . Irbid 221 I0, Jordan

Tel + I I 962796802040

Fax+II 96227095123

Email yousef.k@excite.com
Objectives: To determine cutoff values for body mass index (BMI), waist circumference (WC), waist-to-hip ratio (WHR), and waist-to-height ratio (WHtR) as indicators of metabolic abnormalities in the adult Jordanian population.

Methods: A structured questionnaire was administered to collect relevant information. Anthropometric measurements and biochemical measurements were carried out. Receiver-operating characteristic curve analyses were used to examine the overall discriminatory power of the four anthropometric indices.

Results: WC cutoff values varied from 88.5 to $91.8 \mathrm{~cm}$ in men and from 84.5 to $88.5 \mathrm{~cm}$ in women. The BMI cutoff values varied from 26.2 to $27.2 \mathrm{~kg} / \mathrm{m}^{2}$ in men and from 27.2 to $30.0 \mathrm{~kg} / \mathrm{m}^{2}$ in women. The WHR cutoff values varied from 0.88 to 0.90 in men and from 80.0 to 0.83 in women. The WHtR cutoff values varied from 0.50 to 0.51 in men and women. Of all anthropometric indices, WHtR had the strongest association with each metabolic abnormality in men and women.

Conclusion: BMI, WC, WHR, and WHtR were found to be associated with cardiovascular disease risk factors, with WHtR being the better predictor. We recommend that health care professionals use WHtR, with a cutoff value of 0.5 for screening and counseling Jordanian people.

Keywords: anthropometric indices, metabolic abnormalities, receiver-operating characteristic curve, cutoff values, Jordan

\section{Introduction}

Anthropometric indices, including body mass index (BMI), waist circumference (WC), waist-to-hip ratio (WHR), and waist-to-height ratio (WHtR), are all useful for providing important information on cardiovascular disease (CVD) risk, and have been shown to be associated with CVD risk factors, including hypertension, dyslipidemia, and diabetes. ${ }^{1-3}$ Body mass index (BMI) is a simple measure of body size and is the most widely used method to estimate the prevalence of obesity in a population. Nevertheless, it is a crude index that does not take into account the distribution of body fat. On the other hand, WC, WHR, and WHtR are used as a surrogate for body fat centralization. ${ }^{4,5}$

The best index of obesity that is predictive for CVD risk remains controversial. Some studies have found that total body fat or BMI, rather than distribution of body fat, is the stronger predictor of metabolic risk. ${ }^{6,7}$ Other studies have reported that body fat distribution is a more powerful predictor than BMI for CVD risk factors, diseases, and mortality. ${ }^{8-10}$ Abdominal fat accumulation, as measured by WC or WHR, has been shown to be associated with metabolic and CVD risk, type 2 diabetes mellitus, hypertension, coronary artery disease, and stroke,,$^{8,9,11-13}$ and a stronger association was 
found with abdominal adiposity than with overall adiposity as measured by BMI. ${ }^{14-17}$

WC is a good simple anthropometric index of abdominal visceral adipose tissue, ${ }^{5}$ and is increasingly being accepted as the best anthropometric indicator of metabolic and cardiovascular risk. ${ }^{3,19,20}$ Because the WC measurement has been criticized for not taking into account differences in body height, the WHtR value is suggested as an alternative. ${ }^{1,2,21}$

The anthropometric-metabolic risk relationship is influenced by age, gender, and ethnic differences. The predictive power of some anthropometric indices is population-dependent ${ }^{22}$ and is likely to be different in different ethnic groups. ${ }^{23-27}$ Because populations may differ in the level of risk associated with a particular anthropometric measure, establishing gender- and ethnicity-specific cutoffs is necessary and should be based on their relationship with obesity-related CVD risk factors. The International Diabetes Federation has suggested a redefinition of the metabolic syndrome using WCs adapted for different ethnic groups, ${ }^{28}$ and recommends the use of European cutoff values for WC measurements in people from Middle East Arab populations until more ethnic-specific data are available. In this study, we aimed to determine cutoff values of BMI, WC, WHR, and WHtR as indicators of metabolic abnormalities in the adult Jordanian population and determine their associations with the presence of metabolic abnormalities.

\section{Materials and methods Sampling}

A national population-based household sample was selected from the 12 governorates of Jordan. A complex multistage sampling technique was used to select the households, taking into consideration the geographic distribution of the population as well as urban-rural residence. Because the population is covered by an extensive network of health centers and because the study procedures have to take place in a medical setting, the selection of households was health center-oriented. The health director in each governorate was contacted and asked to identify at least two health centers in which to conduct the study procedures. He was asked to select the health centers so that urban and rural areas in each governorate were represented and the selected centers had enough space to host the study team, participants, and equipment. A total of 31 health centers were identified, and people served by these centers were targeted. A systematic sample of households was selected from the population served by the selected health centers. The number of selected households was approximately proportional to the population in each region.

In each selected area, one day before data collection, two-membered teams (a male and a female each) visited the selected households, explained the purpose of the study, and invited all members aged older than seven years to attend the health centers on the day after an overnight fast. Subjects on regular medications were asked not to take their medications early on that day and to bring all their medications with them to the survey site. The present report deals exclusively with 4590 adults aged over 18 years who responded and agreed to participate in this study.

\section{Data collection}

All field work was carried out between July 1st and November 30, 2009. Participants attended the health centers in the morning $(8-11 \mathrm{am})$, with a minimum fasting time of 10 hours. A pilot-tested structured questionnaire was prepared and administered by trained interviewers to collect the relevant information necessary to answer the current research question and other selected research questions that will be addressed in future publications. The questionnaire sought information on demographics, medical history, and medication use.

\section{Measurements and laboratory analysis}

Anthropometric measurements, including weight, height, hip, and WC were measured with the subjects wearing light clothing and no shoes according to the World Health Organization report. ${ }^{29} \mathrm{WC}$ was measured to the nearest centimeter using a nonstretchable tailors' measuring tape at the midpoint between the bottom of the rib cage and above the top of the iliac crest during minimal respiration. Hip circumference was measured at the widest part of the body below the waist. Waist and hip circumferences were measured using a circumference measuring tape (Seca 200, Hamburg, Germany). BMI was calculated as the ratio of weight in kilograms to the square of height in meters. Readings of systolic and diastolic blood pressure were taken with the subject seated and the arm at heart level, after at least five minutes of rest, using a standardized mercury sphygmomanometer. ${ }^{30}$

For laboratory analysis and all biochemical measurements, two sets of fasting blood samples were drawn from a cannula inserted in the antecubital vein and put into sodium fluoride potassium oxalate tubes for glucose and into lithium heparin vacuum tubes for lipids. Samples were centrifuged at $3000 \mathrm{rpm}$ for 10 minutes within one hour at the survey site, and plasma was transferred to separate labeled tubes and 
transferred immediately in cold boxes filled with ice to the Central Laboratory of the National Center for Diabetes and Endocrinology. All biochemical measurements were carried out by the same team of laboratory technicians and using the same method throughout the study period.

Lipid parameters, ie, total cholesterol, high-density lipoprotein (HDL), low-density lipoprotein (LDL), and triglyceride (TG), and glucose were analyzed for all samples using enzymatic assays. Glucose levels were determined using the enzymatic reference method with hexokinase. ${ }^{31}$ TG values were obtained using COBAS Integra 700 (Roche Diagnostics Ltd, Indianapolis, IN) with the cassette COBAS Integra TG (Roche Diagnostics Ltd) using an enzymatic colorimetric method with glycerol phosphate oxidase and 4-aminophenazone. ${ }^{32}$ Total cholesterol was analyzed using an enzymatic colorimetric method with COBAS Integra Cholesterol Gen.2 (Roche Diagnostics Ltd). HDL and LDL values were obtained on COBAS Integra 700 using a homogeneous enzymatic colorimetric assay. ${ }^{33,34}$ The assays were conducted according to the manufacturer's instructions.

\section{Definition of variables}

Metabolic abnormalities were defined according to the International Diabetes Federation definition, ${ }^{28}$ as follows: elevated TG level $\geq 150 \mathrm{mg} / \mathrm{dL}(1.7 \mathrm{mmol} / \mathrm{L})$, or specific treatment for this lipid abnormality; low HDL cholesterol $<40 \mathrm{mg} / \mathrm{dL}$ $(1.03 \mathrm{mmol} / \mathrm{L})$ in males and $<50 \mathrm{mg} / \mathrm{dL}(1.29 \mathrm{mmol} / \mathrm{L})$ in females, or specific treatment for this lipid abnormality; high blood pressure, ie, systolic blood pressure $\geq 130 \mathrm{mmHg}$ or diastolic blood pressure $\geq 85 \mathrm{mmHg}$, or treatment of previously diagnosed hypertension; high fasting plasma glucose $\geq 100 \mathrm{mg} / \mathrm{dL}(5.6 \mathrm{mmol} / \mathrm{L})$, or previously diagnosed type 2 diabetes.

\section{Statistical analysis}

Data were analyzed using the Statistical Package for Social Sciences software (version 15; SPSS Inc., Chicago, IL). The distributions of continuous anthropometric and clinical variables were checked by plotting histograms and tested using the Shapiro-Wilk W test. The assumption of normality was met for all studied variables. Means and standard deviations were used to describe continuous variables. The differences in anthropometric and clinical characteristics between men and women were analyzed using the Student's $t$-test. The data analysis was performed in men and women separately. Receiver-operating characteristic (ROC) curve analyses $^{35}$ were used to examine the overall discriminatory power, sensitivity and specificity, and corresponding cutoff points of each of the four anthropometric indices for each metabolic abnormality. The overall performance of each anthropometric test for detecting individual metabolic abnormalities was assessed by computing the area under the curve (AUC). For each metabolic abnormality, the AUCs for all anthropometric indices were compared and tested for significant differences using MedCalc version 11.3. (MedCalc Software, Mariakerke, Belgium). The best cutoff points for each anthropometric index were determined at the point on the curve where the sum of sensitivity and specificity was highest. Age-adjusted partial correlation analyses were performed to quantify the independent associations between anthropometric indices. Each anthropometric index was dichotomized for each metabolic abnormality based on the cutoff values established in this study. Multivariate logistic regression analyses were performed to evaluate the associations between the anthropometric indices and individual metabolic abnormalities after adjusting for other variables including age, marital status, income, smoking, and physical activity. Backward stepwise logistic regression analysis was performed using metabolic abnormalities as dependent variables. Because the indices were intercorrelated, only one out of the four indices was introduced into the logistic regression equation at each analysis. A $P$ value of less than 0.05 was considered statistically significant.

\section{Results}

A total of 4590 subjects (1128 men and 3462 women) aged over 18 years, with a mean age of 41.8 (13.4) years were included in this study. Table 1 shows their anthropometric and clinical characteristics according to gender. There were significant differences in anthropometric and clinical parameters between men and women. Men had significantly higher mean weight, height, WC, WHR, WHtR, systolic blood pressure, diastolic blood pressure, fasting blood glucose, and TG levels than women. Other parameters were significantly higher for women compared with those for men. Men had significantly higher prevalence rates of high fasting blood glucose $(34.4 \%$ versus $23.6 \%)$, high blood pressure $(52.9 \%$ versus $36.6 \%)$, elevated TG (62.8\% versus $44.1 \%)$, and low HDL (70.3\% versus $64.2 \%$ ) than women (see Figure 1). The age- and gender-adjusted rates for all metabolic abnormalities were higher for those living in urban areas compared with those living in rural areas.

According to age-adjusted partial correlations among the anthropometric indices, BMI, WC, and WHtR were moderately to strongly intercorrelated in men and women. BMI and WHR were weakly correlated, especially among women. 
Table I Anthropometric and clinical characteristics of 4590 Jordanian adults ( 1128 men and 3462 women) aged over 18 years according to gender

\begin{tabular}{|c|c|c|c|}
\hline \multirow[t]{2}{*}{ Variable } & \multicolumn{2}{|l|}{ Mean (SD) } & \multirow[t]{2}{*}{$P$ value } \\
\hline & Male & Female & \\
\hline Age (year) & $45.3(14.2)$ & 40.7 (I2.9) & $<0.005$ \\
\hline Weight (kg) & $82.4(14.8)$ & $73.7(15.2)$ & $<0.005$ \\
\hline Height (cm) & $169.2(6.8)$ & $156.3(6.2)$ & $<0.005$ \\
\hline Waist circumference $(\mathrm{cm})$ & $93.5(12.7)$ & $85.3(14.6)$ & $<0.005$ \\
\hline Hip circumference $(\mathrm{cm})$ & $103.4(10.0)$ & $107.6(12.2)$ & $<0.005$ \\
\hline Body mass index $\left(\mathrm{kg} / \mathrm{m}^{2}\right)$ & $28.8(5.0)$ & $30.2(6.2)$ & $<0.005$ \\
\hline Waist-hip ratio & $0.90(0.08)$ & $0.79(0.11)$ & $<0.005$ \\
\hline Waist-height ratio & $0.55(0.08)$ & $0.54(0.10)$ & 0.043 \\
\hline $\begin{array}{l}\text { Systolic blood pressure } \\
(\mathrm{mmHg})\end{array}$ & $124.9(17.2)$ & $121.3(17.1)$ & $<0.005$ \\
\hline $\begin{array}{l}\text { Diastolic blood } \\
\text { pressure (mmHg) }\end{array}$ & $81.0(10.9)$ & $78.3(10.0)$ & $<0.005$ \\
\hline Total cholesterol (mg/dL) & $199.4(44.3)$ & $204.0(45.6)$ & $<0.005$ \\
\hline HDL cholesterol (mg/dL) & $36.1(11.1)$ & $46.5(13.3)$ & 0.003 \\
\hline LDL cholesterol (mg/dL) & I I 6.0 (36.9) & II $9.3(37.6)$ & 0.001 \\
\hline $\begin{array}{l}\text { Fasting blood glucose } \\
(\mathrm{mg} / \mathrm{dL})\end{array}$ & II 0.8 (59.0) & $99.6(46.8)$ & $<0.005$ \\
\hline Triglycerides (mg/dL) & 207.7 (I37.8) & I64.I (II5.9) & $<0.005$ \\
\hline
\end{tabular}

Abbreviations: HDL, high-density lipoprotein; LDL, low-density lipoprotein; SD, standard deviation.

The calculated AUCs of anthropometric indices for distinguishing subjects with metabolic abnormalities are summarized in Table 2. For men, there was no significant difference in anthropometric indices to discriminate between subjects based on high blood pressure or low HDL. In regard to elevated TG level, WC and WHtR performed significantly better than BMI. All other indices performed better than BMI for detection of high fasting blood glucose. For women, all other indices performed better than WHR to detect high blood pressure and low HDL. BMI performed the worst to detect high fasting blood glucose. WHtR performed the best for detection of elevated TG levels.

The anthropometric cutoff values for detecting each metabolic abnormality for men and women are shown in Table 3 . The WC cutoff values varied according to metabolic abnormalities from 88.5 to $91.8 \mathrm{~cm}$ in men and from 84.5 to $88.5 \mathrm{~cm}$ in women. The BMI cutoff values varied from 26.2 to $27.2 \mathrm{~kg} / \mathrm{m}^{2}$ in men and from 27.2 to $30.0 \mathrm{~kg} / \mathrm{m}^{2}$ in women. The WHR cutoff values varied from 0.88 to 0.90 in men and from 80.0 to 0.83 in women. The WHtR cutoff values varied from 0.50 to 0.51 in men and women.

Anthropometric indices were tested separately in logistic regression models as main predictor variables for each outcome variable (Table 4). Significant associations were observed between each anthropometric parameter and all metabolic abnormalities. The strength of the association in the regression analysis varied according to gender, anthropometric index, and metabolic abnormality. Of all anthropometric indices, WHtR had the strongest association with each metabolic abnormality in men and women, being the strongest for elevated TG in men and high fasting blood glucose in women. For all logistic regression analyses, there were no significant interactions between anthropometric measures and age.

\section{Discussion}

Based on the AUC, the ability of anthropometric measures to identify subjects with metabolic abnormalities varied according to gender and according to the studied metabolic abnormality in men and women. The finding that none of

Male $\square$ Female

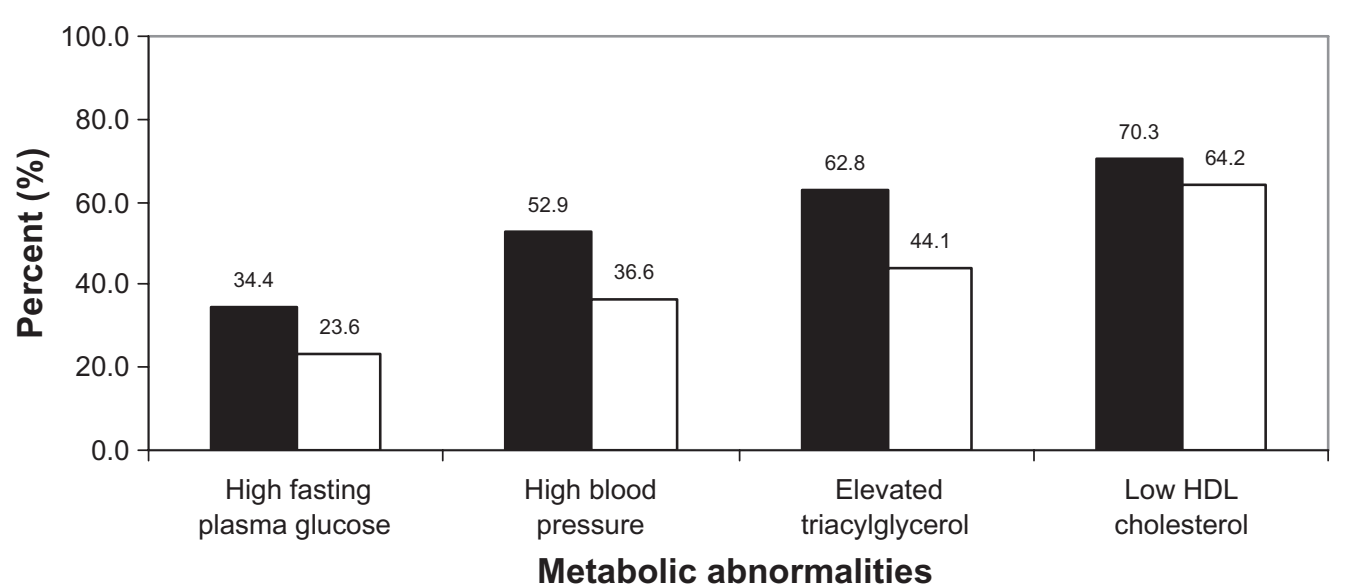

Figure I Prevalence rates of metabolic abnormalities according to the International Diabetes Federation definition for men and women. 
Table 2 Calculated areas under the ROC curves and their $95 \% \mathrm{Cl}$ of anthropometric indices for detecting metabolic abnormalities

\begin{tabular}{|c|c|c|c|c|}
\hline & High blood pressure & High fasting blood glucose & Elevated triacylglycerol & Low HDL \\
\hline & $\operatorname{AUC}(95 \% \mathrm{Cl})$ & AUC (95\% Cl) & AUC ( $95 \% \mathrm{Cl})$ & AUC ( $95 \% \mathrm{Cl})$ \\
\hline \multicolumn{5}{|l|}{ Males } \\
\hline BMI & $0.662(0.630,0.693)$ & $0.63 \mathrm{I}(0.587,0.676) \mathrm{b}$ & $0.638(0.604,0.673) b$ & $0.615(0.578,0.652)$ \\
\hline WC & $0.662(0.63 \mathrm{I}, 0.694)$ & $0.690(0.647,0.733)$ a & $0.666(0.633,0.699) \mathrm{a}$ & $0.621(0.584,0.658)$ \\
\hline WHR & $0.646(0.614,0.678)$ & $0.720(0.678,0.761) \mathrm{a}$ & $0.655(0.622,0.688)$ & $0.636(0.600,0.672)$ \\
\hline WHtR & $0.664(0.633,0.696)$ & $0.702(0.660,0.744) \mathrm{a}$ & $0.662(0.628,0.695) \mathrm{a}$ & $0.610(0.573,0.647)$ \\
\hline \multicolumn{5}{|c|}{ Females } \\
\hline BMI & $0.73 \mathrm{I}(0.7 \mathrm{I}, 0.748) \mathrm{a}$ & $0.683(0.656,0.7 \mathrm{II}) \mathrm{b}$ & $0.695(0.677,0.713)$ & $0.647(0.627,0.666) \mathrm{a}$ \\
\hline WC & $0.722(0.702,0.741)$ a & $0.715(0.686,0.744) \mathrm{a}$ & $0.692(0.673,0.710) \mathrm{b}$ & $0.640(0.620,0.660) \mathrm{a}$ \\
\hline WHR & $0.675(0.655,0.695) b$ & $0.73 \mathrm{I}(0.700,0.76 \mathrm{I}) \mathrm{a}$ & $0.684(0.665,0.703) b$ & $0.622(0.602,0.642) b$ \\
\hline WHtR & $0.725(0.706,0.744) \mathrm{a}$ & $0.723(0.694,0.751) a$ & $0.701(0.683,0.719) \mathrm{a}$ & $0.638(0.618,0.657) \mathrm{a}$ \\
\hline
\end{tabular}

Notes: Within each column, anthropometric parameters with letter "a" are significantly superior to other parameters with letter "b".

Abbreviations: BMI, body mass index; $\mathrm{Cl}$, confidence interval; AUC, area under concentration time curve; HDL, high-density lipoprotein; ROC, receiver-operating characteristic curve; WC, waist circumference; WHR, waist-to-hip ratio; WHtR, waist-to-height ratio.

the anthropometric measures appeared better than the others for detection of all or at least most of the studied metabolic abnormalities may be explained by the moderate-to-strong correlations between these anthropometric measures. When we compared anthropometric measures in regression analysis, the strength of the association varied according to gender, anthropometric index, and metabolic abnormality. In our study, women had higher BMI and lower WC than men. This finding is expected in our population because men are taller than women. Furthermore, BMI calculation is solely dependent on the net weight and height of the individual, and does not consider the distribution of muscle and bone mass. BMI also does not differentiate between body fat and muscle mass. This may result in misleading information with regard to the amount of fat in an individual. Of all anthropometric indices, WHtR had the strongest association with each metabolic abnormality in men and women. There were no significant interactions between anthropometric measures and age, suggesting that the associations did not vary substantially as a function of age and that the results can be generalized to Jordanian adults older than 18 years.

Previous studies have reached different conclusions about which anthropometric index is the best for detecting the risk of metabolic abnormalities. This could be related to the fact that the predictive power of each anthropometric index depends on the studied population ${ }^{22}$ and ethnicity. ${ }^{4}$

Studies in some populations, including in Japan, Canada, and Australia, ${ }^{36-41}$ have reported WHR to be a better indicator of CVD risk than BMI. WHR has been shown to be a better predictor of coronary heart disease than $\mathrm{WC}$ and $\mathrm{BMI}$ in a prospective study of Finnish men aged $42-60$ years. ${ }^{42}$ Furthermore, WHR has been shown to predict CVD risk factors more accurately than BMI, but not WC, in a study of adult Canadian men. ${ }^{43}$ WHR could provide useful clinical information to identify subjects with CVD risk factors because it reflects most of the lifestyle-related risk factors of an individual. ${ }^{44}$

Table 3 Anthropometric parameters cutoff values for detecting high fasting blood glucose, high blood pressure, elevated triacylglycerol level, and low HDL for men and women

\begin{tabular}{|c|c|c|c|c|c|c|c|c|c|c|c|c|}
\hline \multirow[t]{2}{*}{ Index } & \multicolumn{3}{|c|}{ High blood pressure } & \multicolumn{3}{|c|}{ High fasting blood glucose } & \multicolumn{3}{|c|}{ Elevated triacylglycerol } & \multicolumn{3}{|c|}{ Low HDL } \\
\hline & Cutoff & Sens & Spec & Cutoff & Sens & Spec & Cutoff & Sens & Spec & Cutoff & Sens & Spec \\
\hline \multicolumn{13}{|l|}{ Males } \\
\hline BMI & 27.2 & 0.765 & 0.492 & 27.1 & 0.819 & 0.404 & 26.2 & 0.805 & 0.442 & 26.2 & 0.768 & 0.434 \\
\hline WC & 90.2 & 0.728 & 0.524 & 91.8 & 0.763 & 0.522 & 89.6 & 0.75 & 0.516 & 88.5 & 0.727 & 0.472 \\
\hline WHR & 0.88 & 0.75 & 0.51 & 0.90 & 0.751 & 0.596 & 0.89 & 0.702 & 0.558 & 0.88 & 0.673 & 0.551 \\
\hline WHtR & 0.50 & 0.752 & 0.52 & 0.50 & 0.802 & 0.512 & 0.50 & 0.783 & 0.481 & 0.51 & 0.75 & 0.443 \\
\hline \multicolumn{13}{|c|}{ Females } \\
\hline BMI & 30.0 & 0.726 & 0.626 & 29.1 & 0.786 & 0.489 & 28.0 & 0.8 & 0.508 & 27.2 & 0.746 & 0.47 \\
\hline WC & 88.5 & 0.653 & 0.719 & 87.5 & 0.743 & 0.627 & 84.5 & 0.71 & 0.612 & 84.5 & 0.6 & 0.619 \\
\hline WHR & 0.82 & 0.543 & 0.745 & 0.83 & 0.655 & 0.75 & 0.8 & 0.656 & 0.648 & 0.8 & 0.515 & 0.686 \\
\hline $\mathrm{WHtR}$ & 0.51 & 0.621 & 0.76 & 0.51 & 0.778 & 0.611 & 0.50 & 0.714 & 0.626 & 0.50 & 0.492 & 0.724 \\
\hline
\end{tabular}

Abbreviations: HDL, high-density lipoprotein; Sens, sensitivity; Spec, specificity; BMI, body mass index; WC, waist circumference; WHR, waist-to-hip ratio; WHtR, waistto-height ratio. 
Table 4 Relationship between the four anthropometric indices with metabolic abnormalities in multivariate analysis

\begin{tabular}{|c|c|c|c|c|c|c|c|c|}
\hline \multirow[t]{2}{*}{ Index } & \multicolumn{2}{|c|}{ High blood pressure } & \multicolumn{2}{|c|}{ High fasting blood glucose } & \multicolumn{2}{|c|}{ Elevated triacylglycerol } & \multicolumn{2}{|c|}{ Low HDL } \\
\hline & OR* & $95 \% \mathrm{Cl}$ & OR* & $95 \% \mathrm{Cl}$ & OR* & $95 \% \mathrm{Cl}$ & OR* & $95 \% \mathrm{Cl}$ \\
\hline \multicolumn{9}{|l|}{ BMI } \\
\hline Male & 2.32 & $(1.76,3.06)$ & 1.80 & $(1.15,2.82)$ & 2.98 & $(2.22,3.99)$ & 2.42 & $(1.79,3.26)$ \\
\hline Female & 2.63 & $(2.21,3.12)$ & 2.11 & $(1.58,2.80)$ & 2.51 & $(2.13,2.96)$ & 2.00 & $(I .7 I, 2.38)$ \\
\hline \multicolumn{9}{|l|}{ WC } \\
\hline Male & 2.27 & $(1.73,2.99)$ & 2.28 & $(I .5 \mathrm{I}, 3.46)$ & 2.96 & $(2.22,3.93)$ & 2.23 & $(1.66,3.00)$ \\
\hline Female & 2.48 & $(2.08,2.96)$ & 2.59 & $(1.97,3.41)$ & 2.30 & $(1.94,2.72)$ & 1.98 & $(1.67,2.34)$ \\
\hline \multicolumn{9}{|l|}{ WHR } \\
\hline Male & 2.02 & $(I .5 \mathrm{I}, 2.69)$ & 2.39 & $(1.56,3.64)$ & 2.72 & $(2.03,3.64)$ & 2.25 & $(1.66,3.06)$ \\
\hline Female & 1.62 & $(1.36,0.94)$ & 2.31 & $(1.56,3.48)$ & 2.12 & $(1.80,2.50)$ & 1.83 & $(1.54,2.16)$ \\
\hline \multicolumn{9}{|l|}{ WHtR } \\
\hline Male & 2.40 & $(1.80,3.21)$ & 2.41 & $(1.70,3.96)$ & 3.13 & $(2.3 \mathrm{I}, 4.22)$ & 2.48 & $(1.83,3.43)$ \\
\hline Female & 2.49 & $(2.13,2.99)$ & 2.74 & $(2.05,3.66)$ & 2.53 & $(2.13,3.00)$ & 2.12 & $(I .8 I, 2.5 I)$ \\
\hline
\end{tabular}

Notes: *Adjusted for age, marital status, income, smoking, and physical activity.

Abbreviations: HDL, high-density lipoprotein; OR, odds ratio; Sens, sensitivity; Spec, specificity; BMI, body mass index; WC, waist circumference; WHR, waist-to-hip ratio; WHtR, waist-to-height ratio.

While some studies have shown WHtR to be a better predictor of CVD risk factors, ${ }^{1-3,26,35}$ other studies showed that WC is a better predictor of CVD risk factors. ${ }^{5,16}$ Studies in the US have reported that WC is a better predictor than WHR. ${ }^{17,23}$ On the other hand, some studies have reported that total fat and abdominal fat distribution play a similar role in cardiovascular disease, ${ }^{46,47}$ and other studies have found that total fat, rather than its distribution, is a more significant predictor of metabolic risk. ${ }^{6,7}$

The discrepancy in the findings of different studies may be explained by differences in study populations and ethnic groups. Furthermore, studies differed in the site of WC measurement. It has been reported that the ability of WC to predict CVD risk factors differs according to the site of waist measurement. In our study, we measured WC according to the World Health Organization recommendation, ie, at the midpoint between the lower border of the rib cage and the iliac crest.

Our results indicated that ranges of cutoff points for each of these anthropometric indices may be considered. Cutoff points were dependent on gender and metabolic abnormality. Lower cutoff points of BMI and higher cutoff points of WC and WHR were more appropriate for men. Cutoff points for WHtR in men were similar to those for women.

A number of different thresholds for anthropometric indices were suggested. The World Health Organization criteria (1999) defined central obesity as a WHR $>0.90$ in males and $>0.85$ in females, or BMI $>30 \mathrm{~kg} / \mathrm{m}^{2}{ }^{28}$ According to World Health Organization recommendations, the BMI threshold for increasing disease risk in Caucasian populations is $25 \mathrm{~kg} / \mathrm{m}^{2}$ for both men and women, and this value was suggested to be $23 \mathrm{~kg} / \mathrm{m}^{2}$ in Asian men and women. The US National Cholesterol Education Program Adult Treatment Panel III (NCEP-ATP III) defined central obesity as $\mathrm{WC} \geq 102 \mathrm{~cm}$ in males and $\geq 88 \mathrm{~cm}$ in females. ${ }^{49}$ The 2005 International Diabetes Federation consensus definition of the metabolic syndrome used ethnic-specific cutpoints for waist circumference. ${ }^{50} \mathrm{~A}$ WC cutoff of 80-85 cm for men and 75-80 cm for women of Korean or Asian-Pacific background was suggested. ${ }^{3,51}$ In other studies, ${ }^{2,52}$ a cutoff value of 0.5 for WHtR has been proposed as a boundary value.

For BMI, cutoff values varied from 26.2 to $27.2 \mathrm{~kg} / \mathrm{m}^{2}$ in men and from 27.2 to $30.0 \mathrm{~kg} / \mathrm{m}^{2}$ in women. The global standard of a BMI of 25 for measurement of overweight for both genders falls below these ranges. Values of WC fall into a wider range (from 88.5 to $91.8 \mathrm{~cm}$ in men and from 84.5 to $88.5 \mathrm{~cm}$ in women). For men, the upper limit in the range of WC for Jordanians is lower than the cutoff values defined by the NCEP-ATP III $(102 \mathrm{~cm})$ and the International Diabetes Federation 2005 recommendation ( $94 \mathrm{~cm}$ for European men). The International Diabetes Federation cutoff value defined for Asian men $(90 \mathrm{~cm})$ falls within the range of WC for Jordanian men. For women, the WC cutoff point of $88 \mathrm{~cm}$ is close to our upper limit of $88.5 \mathrm{~cm}$. The cutoff values of WHR for men and women (from 0.88 to 0.90 in men and from 80.0 to 0.83 in women) were close to those defined by World Health Organization criteria. Furthermore, the cutoff values of WHtR ( 0.5 to 0.51 in men and women) were close to those defined by others. ${ }^{2,52}$

The finding that WC cutoff limits for the Jordanian population are lower than those for the Western population might be explained by ethnic differences in body composition and by the fact that race/ethnic groups often differ in 
socioeconomic status, cultural factors, diet, physical activity levels, and lifestyle. The choice of which to use could depend on other factors. In Jordan, one should consider that measuring hip circumference in community settings and in the clinic situation is difficult for cultural reasons. Furthermore, inaccurate measurements are expected when undertaken in fully clothed subjects.

The main limitation of this study was the use of crosssectional data to compare the ability of anthropometric indices to detect CVD risk factors. Prospective studies are needed to provide stronger evidence on the predictive power of anthropometric measures. One of the strengths of this study is that we used a representative sample of Jordanian adults which enhances the validity of our findings.

In conclusion, BMI, WC, WHR, and WHtR were found to be associated with CVD risk factors, with WHtR being the better predictor. We recommend that health care professionals in Jordan use WHtR with a cutoff value of 0.5 for screening and counseling people who face higher metabolic risks during physical examinations for many reasons: the value of 0.5 offers a simple but effective index for identifying metabolic abnormalities, in that a single rule of "keeping WC below half of height" may be applied by health professionals to both men and women; closer agreement of values between men and women; comparing AUC for anthropometric indices with metabolic abnormalities, WHtR was either similar to or better than other anthropometric indices to detect metabolic abnormalities; in logistic regression, WHtR had the strongest association with all metabolic abnormalities in both genders; height is a component of this index and this is important because height may influence the observation of fat accumulation and/or distribution; and several reports have indicated that WHtR corresponds better with metabolic risk than other indices.

\section{Acknowledgments}

The authors acknowledge financial support from the Scientific Research Fund at the Ministry of Higher Education and Scientific Research, Jordan.

\section{Disclosure}

The authors report no conflicts of interest in this work.

\section{References}

1. Hsieh SD, Yoshinaga H. Abdominal fat distribution and coronary heart disease risk factors in men - waist to height ratio as a simple and useful predictor. Int J Obes Relat Metab Disord. 1995;19:585-589.

2. Hsieh SD, Yoshinaga H. Waist to height ratio as a simple and useful predictor of coronary heart disease risk factors in women. Intern Med. 1995;34:1147-1152.
3. Ko GTC, Chan JCN, Woo J, et al. Simple anthropometric indexes and cardiovascular risk factors in Chinese. Int J Obes Relat Metab Disord. 1997;21:995-1001.

4. Gallagher D, Visser M, Sepulveda D, Pierson RN, Harris T, Heymsfield SB. How useful is body mass index for comparison of body fatness across age, sex, and ethnic groups? Am J Epidemiol. 1996;143:228-239.

5. Pouliot MC, Despres JP, Lemieux S, et al. Waist circumference and abdominal sagittal diameter: Best simple anthropometric indexes of abdominal visceral adipose tissue accumulation and related cardiovascular risk in men and women. Am J Cardiol. 1994;73: 460-468.

6. Mykkanen L, Laakso M, Pyorala K. Association of obesity and distribution of obesity with glucose tolerance and cardiovascular risk factors in the elderly. Int J Obes Relat Metab Disord. 1992;16: 695-704.

7. Spiegelman D, Israel RG, Bouchard C, Willett WC. Absolute fat mass, percent body fat, and body-fat distribution: Which is the real determinant of blood pressure and serum glucose? Am J Clin Nutr. 1992;55:1033-1044.

8. Stevens J, Keil JE, Rust PF, Tyroler HA, Davis CE, Gazes PC. Body mass index and body girths as predictors of mortality in black and white women. Arch Intern Med. 1992;152:1257-1262.

9. Folsom AR, Kaye SA, Sellers TA, et al. Body fat distribution and 5-year risk of death in old women. JAMA. 1993;269:483-487.

10. Pi-Sunyer FX. Obesity: Criteria and classification. Proc Nutr Soc. 2000;59:505-509.

11. Despres JP, Moorjani S, Lupien PJ, Tremblay A, Nadeau A, Bouchard C. Regional distribution of body fat, plasma lipoproteins, and cardiovascular disease. Arteriosclerosis. 1990;10:497-511.

12. Reeder BA, Senthilselvan A, Despres JP, et al. The association of cardiovascular disease risk factors with abdominal obesity in Canada. CMAJ. 1997; 157:39-45.

13. Ducimetiere P, Richard J, Cambien F. The pattern of subcutaneous fat distribution in middle-aged men and the risk of coronary heart disease: The Paris Prospective Study. Int J Obes. 1986;10:229-240.

14. Haffner S, Mitchell B, Stern M, Hazuda H, Patterson J. Public health significance of upper body adiposity for non-insulin dependent diabetes mellitus in Mexican Americans. Int J Obes Relat Metab Disord. 1992;16:177-184.

15. Richelsen B, Pedersen SB. Associations between different anthropometric measurements of fatness and metabolic risk parameters in non-obese, healthy, middle-aged men. Int J Obes Relat Metab Disord. 1995;19:169-174.

16. Han T, van Leer E, Seidell J, Lean M. Waist circumference action levels in the identification of cardiovascular risk factors: Prevalence study in a random sample. BMJ. 1995;311:1401-1405.

17. Zhu S, Wang Z, Heshka S, Heo M, Faith MS, Heymsfield SB. Waist circumference and obesity-associated risk factors among whites in the third National Health and Nutrition Examination Survey: Clinical action thresholds. Am J Clin Nutr. 2002;76:743-749.

18. Despres JP, Prud'homme D, Pouliot MC, Tremblay A, Bouchard C. Estimation of deep abdominal adipose-tissue accumulation from simple anthropometric measurements in men. Am J Clin Nutr. 1991;54: $471-477$.

19. World Health Organization. Physical Status: The use and interpretation of anthropometry. WHO Technical Report Series 854. Geneva, Switzerland: World Health Organization; 1995.

20. Lemos-Santos MG, Valente JG, Goncalves-Silva RM, Sichieri R. Waist circumference and waist-to-hip ratio as predictors of serum concentration of lipids in Brazilian men. Nutrition. 2004;20: $857-862$.

21. Ashwell M, Lejeune S, McPherson K. Ratio of waist circumference to height may be better indicator of need for weight management. BMJ. 1996;312:377.

22. Molarius A, Seidell JC. Selection of anthropometric indicators for classification of abdominal fatness - a critical review. Int J Obes Relat Metab Disord. 1998;22:719-727. 
23. Ko GT, Tang J, Chan JC, et al. Lower BMI cut-off value to define obesity in Hong Kong Chinese: An analysis based on body fat assessment by bioelectrical impedance. Br J Nutr. 2001;85:135-136.

24. Ko GTC, Chan JCN, Cockram CS, Woo J. Prediction of hypertension, diabetes, dyslipidaemia or albuminuria using simple anthropometric indexes in Hong Kong Chinese. Int J Obes Relat Metab Disord. 1999;23:1136-1142.

25. Molarius A, Seidell JC, Visscher TLS, Hofman A. Misclassification of high-risk older subjects using waist action levels established for young and middle-aged adults results from the Rotterdam Study. J Am Geriatr Soc. 2000;48:1638-1645.

26. Kubena KS, McIntosh WA, Georghiades MB, Landmann WA. Anthropometry and health in the elderly. J Am Diet Assoc. 1991;91: 1402-1407

27. Woo J, Kwok T, Lau E, Li M, Yu LM. Body composition in Chinese subjects relationship with age and disease. Arch Gerontol Geriatr. 1997;26:23-32.

28. Alberti KG, Zimmet P, Shaw J; IDF Epidemiology Task Force Consensus Group. The metabolic syndrome - a new worldwide definition. Lancet. 2005;366:1059-1062.

29. World Health Organization. Measuring Obesity. Classification and description of anthropometric data. Report on a WHO Consultation on the Epidemiology of Obesity. WHO report EUR.ICP=Nut 125. Copenhagen, Denmark: World Health Organization; 1987.

30. World Health Organization. MONICA Manual. Geneva, Switzerland: World Health Organization; 1990.

31. Neeley WE. Simple automated determination of serum or plasma glucose by a hexokinase-glucose-6 -phosphate dehydrogenase method. Clin Chem. 1972;18:509-515.

32. McGowan MW, Artiss JD, Strandbergh DR, Zak B. A peroxidasecoupled method for the colorimetric determination of serum triglycerides. Clin Chem. 1983;29:538-542.

33. Sugiuchi H, Uji Y, Okabe H, et al. Direct measurement of highdensity lipoprotein cholesterol in serum with polyethylene glycolmodified enzymes and sulfated alpha-cyclodextrin. Clin Chem. 1995;41:717-723.

34. Sugiuchi H, Irie T, Uji Y, et al. Homogeneous assay for measuring lowdensity lipoprotein cholesterol in serum with triblock copolymer and alpha-cyclodextrin sulfate. Clin Chem. 1998;445:522-531.

35. van der Schouw YT, Verbeek AL, Ruijs JH. ROC curves for the initial assessment of new diagnostic tests. Fam Pract. 1992;9:506-511.

36. Hartz A, Grubb B, Wild R, et al. The association of waist hip ratio and angiographically determined coronary artery disease. Int J Obes Relat Metab Disord. 1990;14:657-665.

37. Kissebah AH, Krakower GR. Regional adiposity and morbidity. Physiol Rev. 1994;74:761-811.

38. Kortelainen ML, Sarkioja T. Coronary atherosclerosis and myocardial hypertrophy in relation to body fat distribution in healthy women: An autopsy study on 33 violent deaths. Int J Obes Relat Metab Disord. 1994;21:43-49.

39. Kotchen JM, Cox-Ganser J, Wright CJ, Kotchen TA. Gender differences in obesity-related cardiovascular disease risk factors among participants in a weight loss program. Int J Obes Relat Metab Disord. 1993; 17:145-151.
40. Ito H, Nakasuga $\mathrm{K}$, Ohshima A, et al. Detection of cardiovascular risk factors by indices of obesity obtained from anthropometry and dualenergy X-ray absorptiometry in Japanese individuals. Int J Obes Relat Metab Disord. 2003;27:232-237.

41. Welborn TA, Dhaliwal SS, Bennett SA. Waist-hip ratio is the dominant risk factor predicting cardiovascular death in Australia. Med J Aust. 2003;179:580-585.

42. Lakka HM, Lakka TA, Tuomilehto J, Salonen JT. Abdominal obesity is associated with increased risk of acute coronary events in men. Eur Heart J. 2002;23:706-713.

43. Dobbelsteyn CJ, Joffres MR, MacLean DR, Flowerdew G; the Canadian Heart Surveys Research Group. A comparative evaluation of waist circumference, waist-to-hip ratio and body mass index as indicators of cardiovascular risk factors: The Canadian Heart Health Surveys. Int $J$ Obes Relat Metab Disord. 2001;25:652-661.

44. Han TS, Bijan FC, Lean MEJ, Seidell JC. Separate associations of waist and hip circumference with lifestyle factors. Int J Epidemiol. 1998;27:422-430.

45. Rissanen P, Hamalainen P, Vanninen E, Tenhunen-Eskelinen M, Uusitupa M. Relationship of metabolic variables to abdominal adiposity measures by different anthropometric measurements and dual-energy X-ray absorptiometry in obese middle-aged women. Int J Obes Relat Metab Disord. 1997;21:367-371.

46. Ledoux M, Lambert J, Reeder BA, Despres JP. Correlation between cardiovascular disease risk factors and simple anthropometric measures. Canadian Heart Health Surveys Research Group. CMAJ. 1997; 157:46-53.

47. Lundgren H, Bengtsson C, Blohme G, Lapidus L, Sjostrom L. Adiposity and adipose tissue distribution in relation to incidence of diabetes in women: Results from a prospective population study in Gothenburg, Sweden. Int J Obes. 1989;13:413-423.

48. World Health Organization. Definition, Diagnosis and Classification of Diabetes Mellitus and its Complications. Part 1: Diagnosis and classification of diabetes mellitus. Provisional Report of a WHO Consultation. Geneva, Switzerland: World Health Organization; 1999.

49. Expert Panel on Detection, Evaluation, and Treatment of High Blood Cholesterol in Adults. Executive Summary of the Third Report of the National Cholesterol Education Program (NCEP) Expert Panel on Detection, Evaluation, and Treatment of High Blood Cholesterol in Adults (Adult Treatment Panel III). JAMA. 2001;285:2486-2497.

50. The International Diabetes Federation. The IDF consensus worldwide definition of the metabolic syndrome. 2005. Available at: http://www. idf.org/webdata/docs/MetSyndrome_FINAL.pdf. Accessed on 2010 Oct 26.

51. Zhou BF. Predictive values of body mass index and waist circumference for risk factors of certain related diseases in Chinese adults: Study on cut-off points of body mass index and waist circumference in Chinese adults. Biomed Environ Sci. 2002;15:83-96.

52. Ho SY, Lam TH, Janus ED. Waist to stature ratio is more strongly associated with cardiovascular risk factors than other simple anthropometric indices. Ann Epidemiol. 2003;13:683-691.

\section{Publish your work in this journal}

Diabetes, Metabolic Syndrome and Obesity: Targets and Therapy is an international, peer-reviewed open-access journal committed to the rapid publication of the latest laboratory and clinical findings in the fields of diabetes, metabolic syndrome and obesity research. Original research, review, case reports, hypothesis formation, expert opinion and commentaries are all considered for publication. The manuscript management system is completely online and includes a very quick and fair peer-review system, which is all easy to use. Visit http://www.dovepress.com/testimonials.php to read real quotes from published authors. 